\title{
A educação de jovens e adultos no documento final do Seminário Nacional de Educação de Jovens e Adultos
}

Ricardo Macedo Moreira de Paiva ${ }^{1}$

\section{Resumo}

Durante os anos de 1996 e 1997, houve um intenso movimento de educação de jovens e adultos no Brasil. Em especial, um fator teve papel relevante neste cenário: a realização da V Conferência Internacional de Educação de Adultos. Diante deste fator, houve uma grande produção textual. Neste artigo - desenvolvido no interior do quadro teórico da Análise do Discurso, considerando, em especial, as propostas de Dominique Maingueneau - parto de uma suposição: a de que, no texto do Documento Final do Seminário Nacional de Educação de Jovens e Adultos, há um posicionamento discursivo - a educação de jovens e adultos como instrumento de equalização social. Assim, por meio do estudo deste posicionamento este artigo busca refletir sobre como a nossa sociedade tem tratado a educação de jovens e adultos.

Palavras-chave: Educação de Jovens e Adultos; Análise do Discurso; Dominique Maingueneau.

\section{Youth and Adult Education in the final document of the National Youth and Adult Education Seminar}

\section{Abstract}

During 1996 and 1997, there was an intense movement of youth and adult education in Brazil. In particular, one factor played an important role in this scenario: the holding of the 5th International Conference on Adult Education. Given this factor, there was a great textual production. In this article - developed within the theoretical framework of Discourse Analysis, considering, in particular, the proposals of Dominique Maingueneau - I assume an assumption: that, in the text of the Final Document of the National Seminar on Youth and Adult Education, there are a discursive positioning - the education of young people and adults as an instrument of social equalization. Thus, through the study of this position, this article seeks to reflect on how our society has treated the education of young people and adults.

Keywords: Youth and Adult Education; Speech analysis; Dominique Maingueneau.

\section{Introdução}

Durante os anos de 1996 e 1997, houve um intenso movimento de educação de jovens e adultos no Brasil. Por ocasião da V Conferência Internacional de Educação de Adultos (Confintea), que se realizaou em Hamburgo, na Alemanha, houve uma agenda de preparação com a participação de vários segmentos envolvidos com a educação de jovens e adultos. Essa agenda constou de encontros estaduais, seguidos por encontros regionais e culminando em um encontro nacional.

De cada encontro estadual resultou um documento com o diagnóstico, as realizações e

\footnotetext{
${ }^{1}$ CEFET/RJ, Rio de Janeiro, ricardo.moreira1979@hotmail.com
} 
as metas, que se unificaram no encontro regional. Os documentos de cada encontro regional foram discutidos e subsidiaram a elaboração do documento final do Brasil. Supomos que, no texto do Documento Final do Seminário Nacional de Educação de Jovens e Adultos, há um posicionamento discursivo - a educação de jovens e adultos como instrumento de equalização social.

Respondendo a demandas sociais os documentos elaborados para a $V$ Confintea, alinhados com muitos países do ocidente, aderem ao discurso de que a educação de jovens e adultos constitui um dos meios para a construção e consolidação da democracia. Seu objetivo primeiro é, de acordo com os documentos, a construção de novas formas de participação e de exercícios pleno e consciente dos direitos de cidadania.

Paralelamente, nos documentos constituídos para a $\vee$ Confintea, a formação para o trabalho é entendida como uma das dimensões da educação de jovens e adultos. Nestes documentos, o desafio da educação de jovens e adultos, é oferecer uma formação que lhes garanta condições mínimas de ingresso e competição no mercado de trabalho.

Assim, partimos da teoria de que, nos textos dos documentos para a V Confintea, a educação de jovens e adultos aparece como um instrumento de correção de distorções sociais. A pobreza e a desigualdade seriam corrigidas pela formação de cidadãos e pela formação de trabalhadores através da educação de jovens e adultos.

Tendo em vista tais considerações, este artigo tem como objetivo central refletir sobre o funcionamento deste espaço discursivo. Ou seja, por meio do estudo deste posicionamento discursivo, buscamos verificar, com base em preceitos teóricos da Análise do Discurso (AD), como a nossa sociedade tem lidado com o tema da educação de jovens e adultos.

Para tanto, assumimos o primado do insterdiscurso sobre o discurso (MAINGUENEAU, 2008), do que resulta que a undidade de análise é menos o discurso da formação de cidadãos ou da formação de trabalhadores enquanto unidades autônomas, por exemplo, mas, preponderantemente, o espaço de troca entre esses discursos. Levando em conta o cenário brevemente exposto até o momento, defendemos a hipótese de que esses discursos estão inseridos em um mesmo espaço discursivo.

Em conformidade com Maingueneau (2008), entendemos por discurso "uma dispersão de textos cujo modo de inscrição histórica permite definir como um espaço de regularidades 
enunciativas". Observam-se, nessas regularidades, restrições de ordem geográficas, linguísticas, temporais e históricas que condicionam o acontecimento discursivo, especificamente o dizível em um dado espaço e definem, em um mesmo movimento, uma identidade.

Isso significa que as análises aqui realizadas levaram em conta tanto as condições históricas que tornam possível falar de um modo específico sobre a educação de jovens e adultos quanto a textualidade que materializa tais discursos. Assim sendo, buscamos definir que espaço é esse de onde emergem discursos a respeito da formação de jovens e adultos.

\section{A constituição do corpus}

Como dissemos na introdução, o nosso corpus é constituído por fragmentos do texto do Documento Final do Seminário Nacional de Educação de Jovens e Adultos produzido no Brasil para a V Confintea. Assim, a formulação do corpus foi um procedimento realizado através da escolha de um dispositivo material a partir do qual estabelecemos nossos objetivos de pesquisa com base nas questões norteadoras e apoiados em noções fundamentais da teoria da análise do discurso. Ou seja, que nos permite verificar quais discursos atravessam essa materialidade linguística.

A constituição do nosso corpus foi realizada, conforme Jean Jacques Courtine (2014), em uma forma de corpus que procura a determinação das condições de produção de uma sequência discursiva de referência (o documento para a $\vee$ Confintea) e a determinação das condições de formação de um processo discursivo no interior de uma formação discursiva de referência (a educação de jovens e adultos como instrumento de equalização social).

Tentamos mostrar anteriormente que tal processo discursivo, ou processo material e histórico de formação, reprodução e transformação dos enunciados, estava submetido a condições específicas: é, com efeito, sob a dependência do interdiscurso que se constitui o saber próprio a uma formação discursiva nas redes estratificadas de formulações, em que os enunciados se formam, redes que constituem precisamente o processo discursivo (COURTINE, 2014, p.109).

Escolhemos o texto do documento para a V Confintea, como sequência discursiva de referência, em virtude da sua pertinência histórica para a história da educação de jovens e 
adultos naquele momento e, para situar a produção dessa sequência na circulação de formulações trazidas por sequências discursivas que se respondem, se citam, descrevendo as circunstâncias enunciativas dessa produção.

\section{Metodologia da análise}

Investigamos os ditos de determinada época. Aqui, os discursos sobre a educação de jovens e adultos nos documentos para a $\mathrm{V}$ Confintea, existem de determinada forma porque estão imersos em condições históricas próprias. Ao fazer isso, aceitamos a perspectiva de que os discursos não se constituem isoladamente para, em seguida, serem colocados em relação com outros. Sua constituição se dá no interior de um espaço com vários outros discursos.

A identidade dos discursos estruturam-se, então, por meio da relação interdiscursiva, isso faz com que a unidade de análise pertinente deixe de ser os discursos e passe a ser um espaço de trocas entre discursos, o interdiscurso. Assim, passamos do objeto discursivo para o processo discursivo, ao relacionarmos os discursos sobre a educação de jovens e adultos com outros discursos.

Com isso, pudemos identificar os sentidos que ali estão sendo produzidos, a partir de sua análise enquanto materialidade histórica da língua. Quando conseguimos alcançar o processo discursivo, o texto utilizado para acessar os discursos "desapareceu", pois ele era apenas uma parte de um processo maior, já que representa uma unidade textual que pode ser relacionado a outros processos discursivos. Os discursos sobre a educação de jovens e adultos, presentes nos documentos, estavam submetidos a condições específicas. E, que, sob a dependência do interdiscurso, se constituíram os discursos sobre a educação de jovens e adultos.

\section{As condições de produção}

O termo condições de produção do discurso designa um conceito essencial no quadro teórico da Análise do Discurso (AD) e se distancia das noções de circunstância de produção ou contexto. Segundo Possenti: 
[...] o conceito de circunstância será substituído pelo de condições de produção - substituição cuja finalidade é exatamente retirar o funcionamento do discurso da cena pragmática para inseri-lo nas instâncias enunciativas institucionais, marcadas por características amplamente históricas. Trata-se exatamente de uma ruptura com o modo de considerar as 'circunstâncias do discurso' (POSSENTI, 2009, p.367).

A noção de condição de produção tem por base a ideia de que os discursos só podem ser abordados integralmente se forem consideradas as condições sociais e históricas que possibilitam a emergência dos enunciados. Sobre a AD, Pêcheux afirma:

Nosso propósito não é, com efeito, o de estimular uma sociologia das condições de produção do discurso, mas definir os elementos teóricos que permitem pensar os processos discursivos em sua generalidade: enunciaremos a título de proposição geral que os fenômenos linguísticos de dimensão superior à frase podem efetivamente ser concebidos como um funcionamento mas com a condição de acrescentar imediatamente que este funcionamento não é integralmente linguístico, no sentido atual do termo e que não podemos definilo senão em referência ao mecanismo de colocação dos protagonistas e do objeto de discurso, mecanismo que chamamos de "condições de produção" do discurso. Faremos a hipótese de que, a um estado dado das condições de produção corresponde uma estrutura definida dos processos de produção do discurso a partir da língua, o que significa que, se o estado das condições é fixado, o conjunto dos discursos suscetíveis de serem engendrados nessas condições manifesta invariantes semântico-retóricas estáveis no conjunto considerado e que são características do processo de produção colocado em jogo. Isto supõe que é impossível analisar um discurso como um texto, isto é, como uma sequência linguística fechada sobre si mesma, mas que é necessário referi-lo ao conjunto de discursos possíveis a partir de um estado definido das condições de produção[...] (PÊCHEUX, 1969, p.79).

Será, pois, no contexto histórico descrito a seguir que os materiais que compõem o corpus, os documentos para a V Confintea, puderam ser produzidos. Ou seja, as análises que se seguirão são indissociáveis da conjuntura que tornou possível a constituição destes textos.

\section{Educação de jovens e adultos, um dever do Estado}

O ápice da consolidação da educação de jovens e adultos como direito - central no posicionamento discursivo da educação de jovens e adultos como instrumento de equalização social - foi a Conferência Mundial sobre Educação para Todos, ocorrida em 1990, em Jomtien, 
na Tailândia. Nela, a Educação de Jovens e Adultos (EJA), aparece como etapa da educação básica. Foi o momento que consolidou, oficialmente, a educação de jovens e adultos como um fenômeno relativo aos direitos humanos. Na Declaração Mundial sobre Educação para Todos, no artigo 3, do capítulo "Universalizar o Acesso à Educação", está escrito o seguinte:

A educação básica deve ser proporcionada a todas as crianças, jovens e adultos. Para tanto, é necessário universalizá-la e melhorar sua qualidade, bem como tomar medidas efetivas para reduzir as desigualdades. Para que a educação básica se torne equitativa, é mister oferecer a todas as crianças, jovens e adultos, a oportunidade de alcançar e manter um padrão mínimo de qualidade da aprendizagem. A prioridade mais urgente é melhorar a qualidade e garantir o acesso à educação para meninas e mulheres, e superar todos os obstáculos que impedem sua participação ativa no processo educativo. Os preconceitos e estereótipos de qualquer natureza devem ser eliminados da educação. Um compromisso efetivo para superar as disparidades educacionais deve ser assumido. Os grupos excluídos - os pobres; os meninos e meninas de rua ou trabalhadores; as populações das periferias urbanas e zonas rurais; os nômades e os trabalhadores migrantes; os povos indígenas; as minorias étnicas, raciais e linguísticas; os refugiados; os deslocados pela guerra; e os povos submetidos a um regime de ocupação - não devem sofrer qualquer tipo de discriminação no acesso às oportunidades educacionais (UNESCO, 1990, p.3).

Deste modo, apenas quase 50 anos depois de promulgada a Declaração Universal dos Direitos do Homem é que, oficialmente, a educação de jovens e adultos adquiri o status de direito fundamental. A conferência em Jomtien, na Tailândia, consolidou a educação de jovens e adultos como um tema relativo aos direitos humanos, o que fez dela uma pauta específica a ser tratada, descrita e efetivamente trazida a esfera das preocupações do Estado. Percebe-se, assim, que o fato da educação de jovens e adultos adquirir contornos de algo a ser tratado no âmbito das leis e das políticas públicas faz parte de um processo de construção de mecanismos que tentam garantir que direitos considerados fundamentais a todo cidadão sejam reconhecidos e efetivamente respeitados.

\section{Políticas públicas no Brasil}

No contexto nacional, também no final do século XX, temos, no Brasil, a consolidação da educação de jovens e adultos como direito fundamental. Em 1988, com a Constituição Federal (BRASIL, 1988), em seu art. 208, ficou registrado a garantia de ensino, obrigatório e gratuito a 
todos aqueles que a ele não tiveram acesso na idade própria. Vamos recorrer ao texto constitucional para verificar o conteúdo do art. 208:

O dever do Estado com a educação será efetivado mediante a garantia de:

I- educação básica obrigatória e gratuita dos 4 (quatro) aos 17 (dezessete) anos de idade, assegurada inclusive sua oferta gratuita para todos os que a ela não tiveram acesso na idade própria; (Redação dada pela EC n. 59/2009)

II - progressiva universalização do ensino médio gratuito; (Redação dada pela EC n. 14/1996)

III - atendimento educacional especializado aos portadores de deficiência, preferencialmente na rede regular de ensino;

IV - educação infantil, em creche e pré-escola, às crianças até 5 (cinco) anos de idade; (Redação dada pela EC n. 53/2006)

$\checkmark$ - acesso aos níveis mais elevados do ensino, da pesquisa e da criação artística, segundo a capacidade de cada um;

$\mathrm{VI}$ - oferta de ensino noturno regular, adequado às condições do educando; VII - atendimento ao educando, em todas as etapas da educação básica, por meio de programas suplementares de material didático-escolar, transporte, alimentação e assistência à saúde. (Redação dada pela EC n. 59/2009)

$\S 100$ acesso ao ensino obrigatório e gratuito é direito público subjetivo.

$\S 2$ ○ O não oferecimento do ensino obrigatório pelo Poder Público, ou sua oferta irregular, importa responsabilidade da autoridade competente.

$\S 3$ o Compete ao Poder Público recensear os educandos no ensino fundamental, fazer- -lhes a chamada e zelar, junto aos pais ou responsáveis, pela frequência à escola.

Também no final do século XX, no Brasil, foi aprovada a Lei de Diretrizes e Bases da Educação Nacional (BRASIL, 1996), a Lei no 9.394, que traz o art. 37 versando sobre a educação de jovens e adultos. Nela está explícito que:

Art. 37. A educação de jovens e adultos será destinada àqueles que não tiveram acesso ou continuidade de estudos nos ensinos fundamental e médio na idade própria e constituirá instrumento para a educação e a aprendizagem ao longo da vida. (Redação dada pela Lei no 13.632, de 2018)

$\S 1$ 응 Os sistemas de ensino assegurarão gratuitamente aos jovens e aos adultos, que não puderam efetuar os estudos na idade regular, oportunidades educacionais apropriadas, consideradas as características do alunado, seus interesses, condições de vida e de trabalho, mediante cursos e exames.

$\S 2$ 2o O Poder Público viabilizará e estimulará o acesso e a permanência do trabalhador na escola, mediante ações integradas e complementares entre si. $\S 3$ ㅇ A educação de jovens e adultos deverá articular-se, preferencialmente, com a educação profissional, na forma do regulamento (Incluído pela Lei no 11.741, de 2008). 
Como já afirmado, esses documentos indicam diretrizes para a educação de jovens e adultos no Brasil, mas eles representam e se associam a um movimento que se dá em uma escala mais ampla que a nacional. Os termos usados deixam claro o vínculo institucional profundo das políticas públicas nacionais no campo da educação de jovens e adultos com as diretrizes definidas pela UNESCO. De fato, a proposta de educação para jovens e adultos difundida pelo governo brasileiro nas últimas décadas do século XX está inserida em um movimento cuja escala é mundial - ao menos, no que diz respeito ao mundo ocidental.

\section{Educação de jovens e adultos, uma necessidade do mercado de trabalho}

Para que os documentos como a Lei no 9.394 atribuam a responsabilidade pela educação dos jovens e adultos ao Estado, são associados vários aspectos: os desafios históricos que enfrenta a educação pública no Brasil; a realidade social do País e as contradições que geram a busca pela educação entre os jovens e adultos. A inserção do debate em torno da educação dos jovens e adultos no campo dos direitos humanos contribuiu para o entendimento generalizado de que as ações educativas que visem à gestão dos problemas oriundos das contradições sociais que marcam o Brasil são atribuições das esferas governamentais.

No entanto, a educação de jovens e adultos, para o discurso da formação para o mercado de trabalho, tem outras conotações e está profundamente associada ao aumento da produtividade do setor produtivo. O Estado deve - diz o discurso da formação para o mercado de trabalho - reconhecer a responsabilidade pela formação prévia ao emprego, assegurar formação profissional e oferecer oportunidades adequadas para o desenvolvimento de competências que requer o mercado de trabalho.

No artigo, "Educação Básica e Formação Profissional: Uma Visão dos Empresários", documento produzido pela Confederação Nacional da Indústria (CNI) para a Reunião de Presidentes de Organizações Empresariais Ibero-Americanas, realizada no período de 12 a 16 de julho de 1993, em Salvador (BA), temos:

É necessário defender um sistema educativo que forme um homem auto realizado, com uma Educação geral completa, que o torne capaz de assimilar as diversas tarefas e habilidades que a nova empresa exigirá e, por conseguinte,

Periódico Horizontes - USF - Itatiba, SP - Brasil - e020042 
capaz de mover-se no interior da organização social do trabalho. A baixa escolaridade da população economicamente ativa constitui sério obstáculo para uma qualificação profissional adequada ao novo paradigma, baseado na capacidade de absorver e gerar inovações (CNI, 1993, p.16).

Ou seja, para a CNI, o atual estágio de desenvolvimento - marcado pela globalização da economia, pelas inovações tecnológicas e pela emergência de um novo paradigma de organização do trabalho - impõe a implementação de um novo modelo educacional. Os processos educativos, de acordo com o discurso da formação para o mercado, devem estar direcionados diretamente para o trabalho.

A CNI fez circular diversos textos que, em geral, defendem um novo conceito de qualificação, aprendizado ou formação, para acompanhar a restruturação produtiva do país.

\footnotetext{
O conceito de polivalência implica uma formação que qualifique as pessoas para diferentes postos de trabalho dentro de uma família ocupacional e, sobretudo, para complementar as bases gerais, científico-técnicas e socioeconômicas da produção em seu conjunto. Uma formação que articule a aquisição de habilidades e destrezas genéricas e específicas com o desenvolvimento de capacidades intelectuais e estéticas. Implica, portanto, não só a aquisição de possibilidades de pensamento teórico, abstrato, capaz de analisar, de pensar estrategicamente, de planejar e de responder criativamente às situações novas, mas também de capacidades sócio-comunicativas, de modo a poder desenvolver trabalho em equipe e conhecimentos ampliados que possibilitem a independência profissional (CNI, 1993, p.16).
}

Assim, de acordo com a CNI, a educação deve atender às necessidades do setor econômico. Dizia-se que, em razão de necessidades colocadas pelo desenvolvimento tecnológico e por mudanças no sistema capitalista, era necessário repensar os sistemas de educação, tendo em vista adequá-los à nova segmentação do mercado de trabalho.

\section{Dois discursos, uma multiplicidade de acontecimentos}

Em relação às condições de produção apresentadas até aqui, é interessante notar como três acontecimentos parecem interferir de maneira profunda naquilo que ambos os discursos entendem por educação de jovens e adultos:

- A expansão do capitalismo industrial e financeiro, momento em que a educação de 
jovens e adultos passa a ser entendida como educação funcional, isto é, treinamento de mãode-obra mais produtiva, útil ao projeto de desenvolvimento capitalista;

- A consolidação da educação de jovens e adultos como direito na Conferência Mundial sobre Educação para Todos, ocorrida em 1990.

- O esforço de reconstrução, melhor dito, de construção da democracia no Brasil que ganha ímpeto após o fim da ditadura militar, em 1985.

A noção de acontecimento é, também, essencial para a AD e, assim como a de condições de produção, aponta para os laços profundos existentes entre essa disciplina e a história. Ela diz respeito àquilo que foge à estrutura, à irrupção do novo em uma rede causal e que, ainda que imprevisível antes de existir, é explicável a posteriori.

Para a reflexão que faço aqui a respeito dos dois acontecimentos acima citados, recorro a obra de Michel Foucault Arqueologia das ciências e história dos sistemas de pensamento (2000). Nele, o autor, inspirado nos métodos de pesquisa daquilo que ele denomina história serial, constata que o acontecimento não é um fenômeno uniforme, mas é algo que se divide em estratos:

\begin{abstract}
A história serial permite de qualquer forma fazer aparecer diferentes estratos de acontecimentos, dos quais uns são visíveis, imediatamente conhecidos até pelos contemporâneos, e em seguida, debaixo desses acontecimentos que são de qualquer forma a espuma da história, há outros acontecimentos invisíveis, imperceptíveis para os contemporâneos e que são de um tipo completamente diferente (FOUCAULT, 2000, p.291).
\end{abstract}

Assim, a história serial permite descobrir essa multiplicidade de estratos de acontecimentos em que não apenas as grandes revoluções ou descobertas são reconhecidas como tais. Será também essa metodologia de pesquisa que permitirá enxergar uma multiplicidade de "acontecimento difusos" e "atmosféricos" que, no entanto, são determinantes para a história.

Dessa forma, considerando esta definição de acontecimento como fenômeno múltiplo, retomamos os três acontecimentos históricos que parecem ser especialmente relevantes para os discursos que analiso neste artigo. Considerando a proposta foucaultiana exposta acima, a expansão do capitalismo industrial e financeiro, a consolidação da educação de jovens e adultos 
como direito na Conferência Mundial sobre Educação para Todos e o esforço de construção da democracia no Brasil após o fim da ditadura militar podem ser definidos como acontecimentos sob e sobre os quais outras tantas camadas de acontecimentos se formam (a promulgação da a Constituição Federal, a aprovação da Lei de Diretrizes e Bases da Educação Nacional etc.).

Os três episódios mudaram radicalmente o modo como a educação de jovens e adultos é representada simbolicamente no mundo contemporâneo e que, de certa forma, estão no centro do vórtice do posicionamento discursivo - a educação de jovens e adultos como instrumento de equalização social.

\section{Um espaço limítrofe}

Neste momento, o objetivo é analisar como o posicionamento discursivo - a educação de jovens e adultos como instrumento de equalização social - se organiza em termos interdiscursivos. Em última instância, pretendemos verificar em que medida os discursos (formação de cidadãos e formação de trabalhadores) se relacionaram no documento para a $\mathrm{V}$ Confintea.

Para lidar com esses textos que falam, em nossa sociedade, de diferentes modos e com diferentes propósitos, a respeito da educação de jovens e adultos, três conceitos são fundamentais: os de campo, espaço e posicionamento discursivos, divisão do interdiscurso proposta por Maingueneau (2008).

No conjunto de discursos que circulam em uma dada conjuntura - o universo discursivo - é possível recortar campos discursivos, isto é, conjunto de posicionamentos que se delimitam reciprocamente e que se encontram em relação de concorrência. Por sua vez, é possível delimitar, dentro destes campos, subconjuntos de posicionamentos que ao analista pareçam pertinentes. Estes subconjuntos relacionam-se no interior de espaços discursivos e o critério que o analista usa para delimitar estas redes de relações tem por base um saber histórico. Esse conhecimento permite construir hipóteses que serão homologadas ou rejeitadas com o decorrer da pesquisa.

Em relação ao corpus desta pesquisa, foi possível identificar um espaço discursivo - a educação de jovens e adultos como instrumento de equalização social. No interior deste espaço, 
há, pelo menos, dois discursos - formação de cidadãos e formação de trabalhadores - que se consideram, cada um por motivos específicos, aptos a orientar a educação de jovens e adultos.

O que se pode observar, é que este espaço é um intercruzamento de discursos oriundos de pelo menos dois campos consolidados: o político (democracia) e o econômico (capitalista). Ademais, entram em cena dois discursos que não representam um campo, mas que exercem papel fundamental nesta dinâmica discursiva: um discurso pedagógico e o das Organizações Internacionais, especialmente da ONU.

O que parece acontecer, neste caso, é uma aglomeração de discursos em torno de uma temática específica, que um dado recorte do interdiscurso permite identificar. Dada a relevância da educação dos jovens e adultos (por motivos políticos, econômicos, sociais, ...), diversos enunciadores elaboram sua teoria a respeito do que seja o melhor a ser feito quando o objetivo é educar jovens e adultos.

Apesar de não compartilharem, efetivamente, um mesmo campo, os dois discursos polemizam, nos termos de Maingueneau, porque se situam em um mesmo espaço discursivo. E, por sua vez, isso só é possível porque a educação de jovens e adultos é, como afirma Foucault (2000), uma encruzilhada, um ponto de encontro de diversos discursos e um ponto de disputas.

\section{O interdiscurso}

Nos estudos linguísticos, há diversas abordagens em questão. Quero, no momento, retomar uma delas: a discursiva de Maingueneau. Em Gênese dos Discursos (2008), Maingueneau trabalha com a hipótese de que a relação entre os discursos materializa na superfície discursiva uma organização cujas bases estão no interdiscurso.

O interdiscurso será, para Maingueneau, uma rede de trocas na qual diferentes discursos se constituem. É neste sentido que a noção de campo e espaço discursivos se mostram pertinentes, já que delimitam uma região específica do interdiscurso - e não sua totalidade para que o analista observe e descreva as relações que um dado posicionamento mantém com outros posicionamentos vizinhos. Sendo uma rede de trocas definida a priori, cada discurso tem sua gênese atrelada a um conjunto de outros discursos com quem mantém relações.

Por isso, "a unidade de análise pertinente não é o discurso, mas um espaço de trocas 
entre vários discursos convenientemente escolhidos", o que, em termos de gênese, "significa que [os discursos] não se constituem independentemente uns dos outros, para serem, em seguida, postos em relação, mas que eles se formam de maneira regulada no interior de um interdiscurso. Seria a relação interdiscursiva, pois, que estruturaria a identidade" (MAINGUENEAU, 2008, p.21).

\section{A intertextualidade}

A seguir, analisaremos o modo como cada um dos discursos analisados faz referência a outros discursos. Maingueneau (2008) falará, para tratar da presença destes outros enunciadores num determinado discurso, em intertexto e intertextualidade, definindo entre eles a seguinte diferença: enquanto o primeiro conceito diz respeito ao conjunto de fragmentos efetivamente citado pelos enunciadores de um lado do discurso, o segundo refere-se ao sistema de regras implícito às relações intertextuais consideradas legítimas pela competência discursiva.

Este conceito, o de competência discursiva, refere-se ao domínio tácito que os sujeitos têm das regras de formação de enunciados legítimos do seu posicionamento discursivo. Esta competência lhes permite tanto produzir e reconhecer os enunciados que estão em conformidade com o sistema de restrições do discurso do qual são enunciadores, como recusar aqueles que são incompatíveis, isto é, pertencentes a posicionamentos antagonistas.

É importante lembrar que esta noção de competência discursiva se insere em uma teoria do discurso que busca articular língua e história e que, portanto, diz respeito ao modo como um enunciador se apropria da língua (do sistema linguístico) para produzir enunciados típicos do seu posicionamento discursivo em dada conjuntura histórica. Dito de outro modo, não se trata de uma competência inata e puramente linguística, mas de processos linguísticos e discursivos em sua articulação instransponível com a história.

Além disso, o autor distingue entre uma intertextualidade interna, para definir as relações de um discurso com outros do mesmo campo, e uma intertextualidade externa, quando as relações são com discursos de outros campos. No entanto, é preciso salientar que não qualquer alusão a outros discursos que poderá ser identificada como resultado da intertextualidade. Só serão indícios de intertextualidade fragmentos de discursos cuja ideologia é a mesma. 


\section{Posicionamentos discursivos sobre a educação de jovens e adultos}

No Brasil, como já dissemos anteriormente, houve, durante os anos de 1996 e 1997, um instenso movimento de educação de jovens e adultos por ocasião da V Conferência Internacional de Educação de Adultos (Confintea). Ocorreram encontros estaduais, seguidos por encontros regionais e culminando em um encontro nacional. Os encontros resultaram em uma série de documentos com diagnósticos, realizações e metas para a educação de jovens e adultos. No texto do do Documento Final do Seminário Nacional de Educação de Jovens e Adultos produzido na época podemos encontrar dois discursos sobre a educação de jovens e adultos.

Um entende que a função da educação de jovens e adultos é formar cidadãos e, outro, concebe que o papel da educação de jovens e adultos é formar para o mercado de trabalho. Portanto, a educação de jovens e adultos, tem atrás de si, neste espaço discursivo - a educação de jovens e adultos como instrumento de equalização social -, pelo menos dois discursos e, consequentemente, diferentes presupostos sobre formação.

A seguir, veremos, aspectos relevantes da intertextualidade características dos dois discursos no Documento Final do Seminário Nacional de Educação de Jovens e Adultos.

\section{Discurso - formação de cidadãos}

A série de exemplos que veremos a seguir tem como objetivo mostrar como a associação entre educação de jovens e adultos e formação de cidadãos é explicitada nos materiais selecionados.

Vivemos uma época marcada por aceleradas transformações nos processos econômicos, culturais e políticos que determinam novas exigências para que os indivíduos possam partilhar das riquezas e conhecimentos socialmente produzidos, exercendo plenamente sua cidadania e inserindo-se no mundo do trabalho (PAIVA; MACHADO; IRELAND, 1996, p.15, grifos nossos).

A formação de cidadãos democráticos tem por condição a organização de um sistema educacional de qualidade, orientado para o resgate dos valores da cidadania. Não é mais possível avançar sem que se estabeleçam novas relações entre escola e sociedade e critérios de planejamento capazes de gerar oportunidades educacionais mais amplas e diversificadas para os diferentes 
segmentos da população (PAIVA; MACHADO; IRELAND, 1996, p.26, grifos nossos).

Fundada nos valores da democracia, da participação, da eqüidade e solidariedade social, a EJA deve permitir aos educandos mudar a qualidade de sua intervenção na realidade. Seu objetivo primeiro é, pois, a construção de novas formas de participação e de exercícios pleno e consciente dos direitos de cidadania (PAIVA; MACHADO; IRELAND, 1996, p.27, grifos nossos).

Para que o Brasil alcance níveis de desenvolvimento compatíveis com as necessidades e interesses das camadas populares urge que, ao lado de mudanças estruturais no âmbito socioeconômico, sejam implementadas medidas visando transformar os processos de aquisição e desenvolvimento das capacidades humanas. O processo de construção e consolidação da democracia por que passa o nosso país está a exigir de seu povo a consciência crítica do momento histórico (PAIVA; MACHADO; IRELAND, 1996, p.27, grifos nossos).

Em relação aos excertos acima, chamo a atenção para um ponto. O que diz respeito ao fato de que esses textos dão ênfase a formação de cidadãos democráticos. Isto é, associam a existência daquilo que está sendo lido (o Documento Final do Seminário Nacional de Educação de Jovens e Adultos) a construção e consolidação da democracia.

Isso poderia ser irrelevante, ou óbvio, já que os documentos assinados nas outras conferências definem exatamente o compromisso dos governos signatários com a garantia dos direitos democráticos. Porém, em termos semânticos, trata-se de um traço pertinente deste discurso, e que se expressa, textualmente, no material e explicita laços intertextuais específicos.

A presença desta voz parece apontar para o fato de que fundar-se neste discurso tem uma função relevante. Como vimos, as citações presentes em um texto são mais um índice que aponta para um discurso. Os exemplos acima são indicativos de um intertexto bastante típico desse posicionamento. Esse intertexto desempenha um importante papel legitimador.

O texto do documento, analisado neste artigo, enxerga a educação de jovens e adultos a partir de determinada maneira de entender as relações entre educação e sociedade. A falta do exercício pleno e consciente dos direitos de cidadania é, pois, um fenômeno acidental que afeta individualmente a um número maior ou menor de seus membros o que, no entanto, constituiu um desvio, uma distorção que não só pode como deve ser corrigida. A educação de jovens e adultos emerge aí como um instrumento de correção dessa distorção.

Através desse funcionamento discursivo, a educação de jovens e adultos deve garantir a consolidação de uma nação democrática, justa, inclusiva e que promova a emancipação dos 
indivíduos e dos grupos sociais. Este discurso está fundamentado em um posicionamento discursivo que coloca a educação de jovens e adultos como condição para o fim das desigualdades sociais, e como uma força homogeneizadora que tem por função reforçar os laços sociais, promover a coesão e garantir a integração de todos os indivíduos no corpo social.

Temos, então, uma comunidade discursiva que entende ser a educação de jovens e adultos um instrumento de equalização social diante das transformações econômicas, culturais e políticas. Nas palavras de Maingueneau (2008), comunidade discursiva "designa os grupos que existem somente pela e na enunciação de textos que eles produzem e fazem circular: há a imbricação de uma certa configuração textual e do modo de existência de um conjunto definido de indivíduos".

Nesse quadro, a falta de participação e de exercício pleno e consciente dos direitos de cidadania é identificado com a ignorância e com a exclusão dos jovens e adultos do sistema educacional. A educação de jovens e adultos surge como um antídoto à ignorância e como uma forma de inclusão dos jovens e adultos, logo, um instrumento para que os indivíduos exerçam plenamente sua cidadania.

Como podemos ver, no que diz respeito as relações entre educação e sociedade, o texto do documento analisado concebe a educação de jovens e adultos com uma ampla margem de autonomia em face da sociedade. Tanto que lhe cabe um papel decisivo na conformação da sociedade evitando sua desagregação e, mais do que isso, garantindo a construção de uma sociedade democrática.

Assim, as distorções sociais, não são resultados das relações de poder e exploração, mas do bom gerenciamento ou não dos recursos. A culpa das distorções é do próprio indivíduo, as distorções sociais são naturalizadas e não há como evitá-las. Em termos semânticos, trata-se de um traço pertinente deste discurso que se expressa textualmente nos materiais e explicita laços intertextuais específicos.

Estabelece-se, assim, o enlaçamento de uma representação de educação - uma educação como solução para os problemas sociais - e de uma atividade enunciativa - através da qual os textos para a $\vee$ Confintea reafirmam esse papel da educação de transformar o mundo. É deste modo de apresentação que emerge uma imagem da educação de jovens e adultos como um instrumento de equalização social. 


\section{Discurso - formação de trabalhadores}

Até este momento, vimos como a educação de jovens e adultos, no Documento Final do Seminário de Educação de Jovens e Adultos, visa garantir a formação de cidadãos. Veremos, agora, outro intertexto característico do documento para a $\mathrm{V}$ Conferência Internacional de Educação de Adultos.

Como já mencionado, essa outra proposta de educação, defende que a educação de jovens e adultos contribua para a formação para o trabalho. Observar o texto citado deste posicionamento tem como objetivo explicitar como tal proposta se justifica.

Vejamos, assim, um grupo de exemplos de fragmentos que são efetivamente citados ao longo do texto:

A formação para o trabalho, entendida como uma das dimensões da educação continuada de jovens e adultos, deve articular-se à educação geral e atender aos fins da educação nacional (PAIVA; MACHADO; IRELAND, 1996, p.27, grifos nossos).

Vivemos uma época marcada por aceleradas transformações nos processos econômicos, culturais e políticos que determinam novas exigências para que os indivíduos possam partilhar das riquezas e conhecimentos socialmente produzidos, exercendo plenamente sua cidadania e inserindo-se no mundo do trabalho (PAIVA; MACHADO; IRELAND, 1996, p.15, grifos nossos).

Não é só o aluno adulto, mas também o adolescente; não apenas aquele já inserido no mercado de trabalho, mas o que ainda espera nele ingressar; não mais o que vê a necessidade de um diploma para manter sua situação profissional, mas o que espera chegar ao ensino médio ou à universidade para ascender social e profissionalmente (PAIVA; MACHADO; IRELAND, 1996, p.19, grifos nossos).

As exigências da sociedade contemporânea impõem à EJA alcançar novas dimensões, propiciando a formação integral do ser humano e a consciência de suas potencialidades como ser criador, de modo a assegurar o acesso aos bens culturais, aos meios de preservação do meio ambiente e promoção do desenvolvimento sustentável, aos conhecimentos científicos e tecnológicos necessários à participação social e inserção no mundo do trabalho (PAIVA; MACHADO; IRELAND, 1996, p.28, grifos nossos).

Nos excertos, as referências são, exclusivamente, ao mundo do trabalho, e o tema em questão é sempre a formação para o trabalho - que é, como já dito, um tema que caracteriza 
educação de jovens e adultos, no documento, como um instrumento de equalização social. Assim, a educação de jovens e adultos, é uma forma de enfrentar distorções sociais como o desemprego e desigualdade social.

Compreende-se, então, que para esse posicionamento, as distorções sociais não serão identificadas com a ignorância nem será detectada a partir da exclusão. O desempregado será o incompetente, isto é, o ineficiente e improdutivo. A educação de jovens e adultos estará cumprindo sua função de equalização social na medida em que formar indivíduos eficientes, portanto, capazes de darem sua parcela de contribuição para o aumento da produtividade da sociedade. A educação de jovens e adultos é concebida, pois, como um subsistema, cujo funcionamento eficiente é essencial ao equlíbrio do sistema social de que faz parte.

\section{Considerações finais}

Vimos que, a educação de jovens e adultos, no texto do Documento Final do Seminário Nacional de Educação de Jovens e Adultos, documento constítuido para a $\mathrm{V}$ Confintea, a educação de jovens e adultos aparece como um instrumento de correção de distorções sociais. A pobreza e a desigualdade seriam corrigidas pela formação de cidadãos e pela formação de trabalhadores através da educação de jovens e adultos.

Percebe-se, que esse posicionamento, entende as as relações entre educação e sociedade de determinada maneira. De acordo com esse posicionamento, a sociedade é harmoniosa, tendendo a integração de seus membros. A pobreza e o desemprego são fenômenos acidentais que afetam individualmente a um número maior ou menor de seus membros o que, no entanto, constitui uma distorção a ser corrigida.

A educação de jovens e adultos constitui, pois, uma força homogeneizadora que tem por função reforçar os laços sociais, promover a coesão e garantir a integração de todos os indivíduos no corpo social. Ou seja, ela tem um papel decisivo na sociedade evitando sua desagregação e, mais do que isso, garantindo a construção de uma sociedade igualitária.

Esse posicionamento, diferente da nossa opinião, não concebe a sociedade como sendo essencialmente marcada pela divisão entre grupos ou classes antagônicas. Entendemos que, as distorções sociais, são fenômenos inerentes à própria estrutura da sociedade. Isto porque o 
grupo ou classe dominante se apropria da produção social tendendo, em consequência, a perpetuação das desigualdades sociais.

Nesse contexto, a educação de jovens e adultos, no texto do Documento Final do Seminário Nacional de Educação de Jovens e Adultos, documento constítuido para a V Confintea, cumpri a função de reforçar a dominação da classe dominante. Nesse sentido, a educação de jovens e adultos, longe de ser um instrumento de correção de distorções sociais, se converte num fator de manutenção da desigualdade.

\section{Referências}

BRASIL. [Constituição (1988)]. Constituição da República Federativa do Brasil de 1988. Brasília, DF: Presidência da República, [2018]. Disponível em: http://www.senado.gov.br/legislacao/const/con1988/CON1988_05.10.1988/CON1988.pdf. Acesso em: 20 jul. 2020.

BRASIL. Ministério do Trabalho e Emprego. Educação profissional: um projeto para o desenvolvimento sustentado. Brasília, 1995.

BRASIL. Lei no 9.394, de 20 de dezembro de 1996. Estabelece as diretrizes e bases da educação nacional. Disponível em: http://bd.camara.leg.br. Acesso em: 20 jul. 2020

CNI/ACE/OIE. Educação básica e formação profissional: uma visão dos empresários. Salvador: Confederação Nacional da Industria, 1993.

COURTINE, J. J. Análise do discurso político: o discurso comunista endereçado aos cristãos. São Carlos: EdUFSCar, 2014.

FOUCAULT, M. Arqueologia das ciências e história dos sistemas de pensamento. Rio de Janeiro: Forense Universitária, 2000.

MAINGUENEAU, D. Gênese dos discursos. São Paulo: Parábola Editorial, 2008.

PAIVA, J.; MACHADO, M. M.; IRELAND, T. Educação de jovens e adultos: uma memória contemporânea 1996-2004. Documento Final do Seminário Nacional de Educação de Jovens e Adultos, Natal, p.15-35. 1996.

PÊCHEUX, M. Por uma análise automática do discurso: uma introdução à obra de Michel Pêcheux. Campinas: Editora da UNICAMP, 1997.

POSSENTI, S. Questões para analistas do discurso. São Paulo: Parábola Editorial, 2009. 
UNESCO. Declaração mundial sobre educação para todos e plano de ação para satisfazer as necessidades básicas de aprendizagem. 1990. Disponível em http://unesdoc.unesco.org/images/0008/000862/086291por.pdf. Acesso em 20/5/2019.

\section{AGRADECIMENTOS}

Aos professores Maria Cristina Giorgi e Maicon Jeferson da Costa, por toda a sua disponibilidade, atenção e compreensão, tornando possível a realização deste trabalho.

Aos professores da banca, Fabio Sampaio de Almeida, Taís Silva Pereira e Dayala Paiva de Medeiros Vargens pela leitura do meu trabalho.

À minha esposa, Patricia Fernanda Neves, pela presença sempre amorosa, pelo cuidado, pela parceria na vida.

Aos funcionários do Centro Federal de Educação Tecnológica (CEFET), parte essencial da engrenagem que faz o instituto funcionar.

Aos professores do Programa de Pós-Graduação em Filosofia e Ensino (PPFEN), por ter me ensinado o valor do saber.

Aos amigos do Programa de Pós-Graduação em Filosofia e Ensino (PPFEN), por terem tornado meu percurso mais alegre.

Recebido fevereiro 2020.

Aprovado junho 2020. 